\title{
TTR
}

Traduction, terminologie, re?daction

\section{Translating for the Theatre: The Case Against Performability}

\section{Susan Bassnett}

Volume 4, numéro 1, 1st semester 1991

Languages and Cultures in Translation Theories

URI : https://id.erudit.org/iderudit/037084ar

DOI : https://doi.org/10.7202/037084ar

Aller au sommaire du numéro

Éditeur(s)

Association canadienne de traductologie

ISSN

0835-8443 (imprimé)

1708-2188 (numérique)

Découvrir la revue

Citer cet article

Bassnett, S. (1991). Translating for the Theatre: The Case Against Performability. TTR, 4(1), 99-111. https://doi.org/10.7202/037084ar d'utilisation que vous pouvez consulter en ligne.

https://apropos.erudit.org/fr/usagers/politique-dutilisation/ 


\title{
Translating for the Theatre: The Case Against Performability
}

\author{
Susan Bassnett
}

In the history of translation studies, less has been written on problems of translating theatre texts than on translating any other text type. The generally accepted view on this absence of theoretical study is that the difficulty lies in the nature of the theatre text, which exists in a dialectical relationship with the performance of that same text and is therefore frequently read as something 'incomplete' or 'partially realized'. In the twentieth century, the notion of a spatial or gestural dimension that is seen as inherent in the language of a theatre text becomes an issue of considerable importance, and a whole series of theoreticians attempt to define the nature of the relationship between the verbal text on the page and the supposedly gestic dimension that is somehow embedded in that text, waiting to be realized in performance. ${ }^{1}$

The notion of the gestic text that is somehow encoded into the written in a way that so far has defied any definition is particularly problematic for the interlingual translator. If this concept is accepted, then, as I have argued elsewhere, the translator is being

1. See for example Keir Elam, Semiotics of Theatre and Drama (London, Methuen, 1980); Andre Helbo, ed. Theory of Performing Arts (Amsterdam/Philadelphia, John Benjamins, 1987); Marcello Pagnini, "Per una semiologia del teatro classico," Strumenti critici, no. 12 (1970), pp. 122-140; Paola Gulli Pugliatti, I segni latenti (Messina/Florence, Sant'Anna, 1976); Franco Ruffini, Semiotica del testo (Rome, Bulzoni, 1978); Anne Ubersfeld, Lire le thêâtre (Paris, Editions sociales, 1978). 
asked to do the impossible, that is, to treat a written text that is part of a larger complex of sign systems, including paralinguistic and kinesic signs, as if it were a literary text created for the page and read as such. ${ }^{2}$ The task of the translator thus becomes superhuman - he or she is expected to translate a text that a priori in the source language is incomplete, containing a concealed gestic text, into the target language which should also contain a concealed gestic text. And whereas Stanislawski or Brecht would have assumed that the responsibility for decoding the gestic text lay with the performers, the assumption in the translation process is that this responsibility can be assumed by the translator sitting at a desk and imagining the performance dimension. Common sense should tell us that this cannot be taken seriously.

Wrestling with the same conundrum, Patrice Pavis has recently argued that where translation for the stage is concerned, "real translation takes place on the level of the mise en scene as a whole" and he goes on to say:

translation in general and theatre translation in particular has changed paradigms: it can no longer be assimilated to a mechanism of production of semantic equivalence copied mechanically from the source text. It is rather to be conceived of as an appropriation of one text by another. Translation theory thus follows the general trend of theatre semiotics, reorienting its objectives in the light of a theory of reception. ${ }^{3}$

This is fair enough, so far as it goes. Translation theory has indeed been reorienting its objectives for some years now, and the impact of polysystem theory and manipulation theory has been strongly felt worldwide. But Pavis still insists on a hierarchical

2. Susan Bassnett, "Ways Through the Labyrinth: Strategies and Methods for Translating Theatre Texts," Theo Hermans, ed. The Manipulation of Literature (London, Croom Helm, 1985, pp. 87103).

3. Patrice Pavis, "Problems of Translation for the Stage: Intercultural and Post-modern Theatre," Hanna Scolnicov and Peter Holland, eds., The Play out of Context: Transferring Plays from Culture to Culture (Cambridge, Cambridge University Press, 1989, pp. 25-45). 
relationship, repeating the notion that 'real' translation takes place on the level of the mise en scene, in other words, that a theatre text is an incomplete entity. This means that his unfortunate interlingual translator is still left with the task of transforming unrealized text $A$ into unrealized text $B$, and the assumption here is that the task in hand is somehow of a lower status than that of the person who effects the transposition of written text into performance.

Translation is, and always has been, a question of power relationships, and the translator has all too often been placed in a position of economic, aesthetic and intellectual inferiority. In the theatre this is often seen at its most extreme; the contemporary British policy, as practised by the National Theatre, for example, is a case in point, for translators are commissioned to produce what are termed 'literal' translations and the text is then handed over to a well-known (and most often monolingual) playwright with an established reputation so that larger audiences will be attracted into the theatre. The translation is then credited to that playwright, who also receives the bulk of the income.

The link between theatre translation and crude economic concerns is a long established one. The case of British theatre today is by no means unique, and a glance at repertoires in the London theatres in the late seventeenth and early eighteenth centuries also reveals the importance of translation (frequently unacknowledged) as an important box office criterion. In 1637 Joseph Rutter produced a translation of Corneille's Le Cid, and by 1663 Sir William D'Avenant was complaining about the verbosity of the French:

The French convey their Arguments too much

In Dialogue: their Speeches are too long. ${ }^{4}$

The result was large-scale amendments of French playtexts in their English versions, some of which featured prominently in London repertoires for years. In an age when theatre-going was big business, translated texts in whatever bowdlerized form provided

4. William D'Avenant, The Playhouse to Be Lett (1663), Act I, quoted in Allardyce Nicoll, A History of English Drama 16601900, Vol. l, Restoration Drama (Cambridge, Cambridge University Press, 1961). 
fodder for theatres, just as today, in the market-force economic climate of Thatcher's and post-Thatcher's Britain, the key factor is the size of the audience and the price they are willing to pay for tickets, certainly not the ethics of translation. In such a climate, ethical considerations are diminished; texts are cut, reshaped, adapted, rewritten and yet still described as 'translations'. Sometimes the useful English word 'version', which implies that the translation has been radically revised for the target culture is used instead of the term 'translation'.

The history of theatre translation into English is inextricably bound up with economics, but, as we might expect, an alternative explanation of a more respectable kind is generally offered by those engaged in this business. It is principally among English language translators, directors and impresarios that we find the use of the notion of 'performability' as a criterion essential to the translation process. It is this term that is used to excuse the practice of handing over a supposedly literal translation to a monolingual playwright, and it is this term also that is used to justify substantial variations in the target language text, including cuts and additions. Moreover, the term 'performability' is also frequently used to describe the indescribable, the supposedly existent concealed gestic text within the written.

In the years that I have been involved both as a translator of theatre texts and as a theoretician, it has been this term that has consistently caused the most problems. It has never been clearly defined, and indeed does not exist in most languages other than English. Attempts to define the 'performability' inherent in a text never go further than generalized discussion about the need for fluent speech rhythms in the target text. What this amounts to in practice is that each translator decides on an entirely ad hoc basis what constitutes a speakable text for performers. There is no sound theoretical base for arguing that 'performability' can or does exist.

If a set of criteria ever could be established to determine the 'performability' of a theatre text, then those criteria would constantly vary, from culture to culture, from period to period and from text type to text type. For beneath many of the vague generalizations about theatre translation is a curiously old-fashioned notion of universality, the idea that the play, with its multi-layered structure, is a constant across cultural boundaries, and this is clearly historically inaccurate to say the least. It is also significant that the 
term 'performability' first makes its appearance in the twentieth century and then most frequently in connection with theatre texts that are either naturalist or post-naturalist. Assumptions about the relationship between written text and performance in the field of theatre translation are therefore often oversimplistic and based on a concept of theatre that is extremely restricted.

Naturalist drama imposed the idea of the scripted play, the preperformance text that actors and directors alike have to study in minute detail and reproduce with some measure of fidelity. So powerful has this concept of the playtext been that theatre history has frequently been reshaped to fit texts produced in pre-naturalist eras into the same mould. So despite the fact that Shakespeare's texts exist in Quarto and Folio forms, and versions of the same play can vary considerably, there has been a tendency to consider those same texts as sacred cows and to assume that they were written as unified wholes and then reproduced by actors. In Hamlet and in A Midsummer Night's Dream Shakespeare himself gives us a portrait of performers trained to improvise, to reproduce set speeches, to learn new parts and, in short, to assemble a playtext from a combination of the written and the physical, the new and the memorized, and we know from the commedia dell'arte tradition that this mode of creating a performance was standard Renaissance practice. The fragmentary written text, such as it was, functioned as a blueprint on which performers could build from their own experience. The notion of the fixed playtext, with its detailed stage directions, with each player's speech patterns carefully calculated by the playwright did not at that time exist.

It is significant that when we come to the nineteenth century and the great wave of naturalist playwriting the role of the author increases in significance. In terms of the texts, this can be seen by the growth of the convention of the detailed stage direction, stage directions which at times become prose narrative or even interior monologue. We may justifiably ask what is the function of this kind of writing, whether stage direction as such, i.e., an instruction to the performer, whether instructions to the director on how to conceive of the character or whether prose narrative that assists with the reading of the text on the page. For in post-naturalist playtexts there is this dichotomy - on the one hand much is made of the psychological realism of characters in given situations (and we may think of Stanislawski's method of instructing actors on how to build a character, from the inside outwards, as an example of performance style well suited to this kind of text); on 
the other hand the text is written to be read in much the same way as a piece of prose narrative is read. In fact, there is in existence what might be described as a whole sub-category of dramatic texts, set out in dialogue but never meant for performance. Further research into this type of text is needed, but what it implies is a convention of reading which meant that the playtext format was an entirely acceptable mode, even though completely divorced from any possibility of performance. The theories of the incompleteness of the theatre text are cast in serious doubt if we consider this category of texts. A further feature of this problem, beyond the scope of this paper, emerges if a text originally written as a nonperformable play in dialogue form is then staged at another moment in time, in other words if a text apparently devoid of a gestic dimension is transposed despite the wishes of the author into physical performance.

Performance, which means inevitably interpretation, interrupts the relationship between writer, text and reader, and imposes an additional dimension which many writers have found undesirable. Luigi Pirandello, who saw actors, translators and illustrators all as betrayers of the author, describes the presence of the actor as an intrusion and says:

How many times does some poor dramatic writer not shout 'No, not like that!' when he is attending rehearsals and writhing in agony, contempt, rage and pain because the translation into material reality (which, perforce, is someone else's) does not correspond to the ideal conception and execution that had begun with him and belonged to him alone.

Pirandello's vision of the playtext is that it belongs primarily to the writer and that performance is a form of attack on the writer's intentions. Bernard Shaw, for example, does not go so far, but he does take inordinate care in his lengthy stage directions to control even the physical appearance of his characters. In other words, what post-naturalist theatre demands is a high degree of fidelity to the written text on the part of both director and performers, and once that idea of fidelity was established, it was

5. Luigi Pirandello, "Illustrators, Actors and Translators," transl. Susan Bassnett, The Yearbook of the British Pirandello Society, no. 7 (1987), pp. 58-79. 
imposed on the whole gamut of theatre texts regardless of their quintessential difference. The implications for the interlingual translator gradually emerged: if performers were bound in a vertical master-servant relationship to the written text, so also should translators be. The power of the written playtext changed completely in the nineteenth century, and methods of training actors changed accordingly, as did their status. The key figure to emerge in this new concept of theatre is the director, yet another link in the chain separating the writing process from the performance. Bound in this servile relationship, one avenue of escape for translators was to invent the idea of 'performability' as an excuse to exercise greater liberties with the text than convention allowed. That term has then been taken up by commentators on theatre translation, without regard for its history, and has entered into the general discourse of theatre translation, thereby muddying the already murky waters still further.

Most of the existing literature on theatre translation consists of case studies of individual translations and translators, translators' prefaces or generalized remarks. The pioneering work of Jiři Levy has never really been improved upon. When Ortrun Zuber edited her collection of essays entitled The Languages of Theatre in 1980, she noted in her Introduction that it was "the first book focusing on translation problems unique to drama," and expressed a belief that the study of "drama in translation studies" might constitute a new discipline. ${ }^{6}$ Certainly, there have been no comparable studies in the field of theatre to those which have been developing for so long on poetry and prose, but rather than trying to argue for the existence of what is plainly not a new discipline at all, it seems more important to try to clarify certain historical implications, which might perhaps help to explain the absence of work in this field.

Two principal modes of theatre translation seem to have existed side by side certainly since the seventeenth century. One is the much documented translation of classical Greek and Roman playwrights, to which in the latter part of the eighteenth century can be added the Elizabethans, and this form of translation perceived the playtext as essentially a poetic text, as a unit to be read

6. Ortrun Zuber, ed. The Languages of Theatre: Problems in the Translation and Transposition of Drama (London, Pergamon Press, 1980). 
on the page and translated as a literary text. The performance dimension is absent; what matters is the availability of texts for reading in the ferment of nationalistic language revivals that spread across Europe. The history of such translations is to be found in the history of the translation of poetry, for the principal area of debate lay in the creation of suitable verse forms in the target language. The history of Shakespeare translation until recent times lies within the history of verse translation, not of theatre translation, which is not to say that many of those translations have not been (and sometimes still are) performed. However, if we consider the vast amount of critical commentary on this mode of translation, the question of the performability of the text is simply not there. The principal criteria for the translators were the power of the verse form and the status of the written text.

At the same time, however, the theatre boom experienced particularly in northern Europe led to a rapid turnover in speedy hack translations that could be adapted for performance in the new theatres by the emergent companies. Texts were anything but sacred, and were reshaped according to very basic needs audience expectations, size of company, repertoire of performers, limitations of time and space etc. So, for example, in the eighteenth century we have the case of a revised King Lear with a happy ending, or the phenomenally successful translation of Racine's Andromache retitled The Distressed Mother which stayed in repertoire for years and provided a vehicle for a succession of actresses to extoll the strength of woman who triumphs over adversity. From these two very different, but contemporary modes of translation, what we can deduce is that translations for performance have tended away from notions of 'fidelity' to the source text, whilst 'poetic' translations of theatre texts have suscitated a whole range of debates on the nature of fidelity to verse form. The question now to be asked is whether performability ever featured as an intrinsic element in either of these modes. Certainly in the commercial theatre, performability, had the term existed at all in previous ages, would have been defined in terms of basic, practical necessity and nothing more.

Recent work in theatre semiotics has raised the question of variations in the reading of theatre texts. A number of reading strategies have been identified - the pre-performance literary reading which involves an imaginative spatial dimension by the individual as in the reading of a novel, the post-performance literary reading which contains remembered signs from the expe- 
rience of having seen the play, the director's reading which involves shaping the text within a larger system of theatrical signs, a performer's reading, which focuses on one role and other similarly focussed readings by lighting technicians etc. The reading that has never been discussed is the interlingual translator's reading, hence the absence of a terminology and the continuation of vague, illdefined notions of what actually goes on. Yet surely there is such a notion as the translator's reading, and further research is required to investigate what this might consist of and in what way, if any, it might diverge from the translator's reading of a prose text.

Any director or performer who has worked in more than one country is all too aware of the enormous differences in rehearsal convention, in performance convention and in audience expectation. This is strikingly obvious, even where cultures appear relatively close, as in Europe. What can also easily be overlooked is the fact that theatres in different cultures may exist in different stages of development. So, for example, discussing the contemporary Chinese theatre, Vicki Ooi points out that:

The (Chinese) translator feels his deepest sense of loss and his own inadequacy when he searches into the dramatic language which he has inherited from his own drama. He finds that the language available is useful only for direct, descriptive, textural communication. There does not exist a subtextual convention in modern Chinese drama for him to fall back on. This is when the translator has to teach himself to work in a much more self-conscious way towards finding a new language.

In such a situation, any talk of 'performability' must be discounted. Vicki Ooi's paper discusses in detail a Cantonese translation of Eugene O'Neill's Long Day's Journey into Night, and the thrust of her argument is that the only strategy open to the translator, given the completely different conventions of performance that exist between the source and target cultures, is to maintain the 'strangeness' or 'foreigness' of O'Neill's work so that "the translation must be a discovery to the translator as to his readers." There is no question here of an abstract concept of

7. Vicki Ooi, "Transcending Culture: A Cantonese Translation and production of O'Neill's Long Day's Journey into Night," in Zuber op. cit., pp. 51-69. 
performability that may exist in the source text and may be creatable in the target text; the task of the translator is seen as that of extending the boundaries of the target culture dramatic language by ensuring that care is taken not to radically change the source text.

'Performability' is equally nonsensical in other forms of dramatic text, either where performance conventions of the source culture were ritualized and performing conventions may be only scantily known to us (e.g. the ancient Greek theatre) or where there is no evidence of performance having taken place at all. The case of the plays of Hrostvitha von Gandersheim, the tenth century nun who wrote plays after the manner of Terence is one such example. Since the discovery of the plays in the Emmeram-Munich Codex in 1493 , debate has raged as to whether they were written for performance and indeed, whether they were performed at all. Significantly, known attempts at performance date from the early twentieth century, thereby providing yet another example of the way in which the post-naturalist theatre reinterprets texts from an earlier period. It is also interesting to note, though space here does not allow extensive discussion, that translations of the plays (originally written in Latin verse) fall into two categories - either deliberately archaizing devices are used and the verse form chosen subordinates all other considerations, or linguistic devices are used in the dialogue to convey a sense of 'naturalism' and 'modernity'. One small passage from Dulcitius will suffice as an example of these two strategies:

DIOCLETIANUS: CHIONIA:

DIOCLETIANUS:
Ista insanit; admoveantur. Mea germana non insanit, sed tui stultitiam iuste reprehendit.

Ista inclementius bachatur; unde nostris conspectibus aeque subtrahatur, et tertia discutiatur.

Version I:

DIOCLETIANUS: CHIONIA:

DIOCLETIANUS:
The girl raves. Take her away. My sister does not rave. She is right.

This maenad seems even more violent that the other!

Remove her also from our presence and we will question the third. 
Version II:

DIOCLETIANUS: CHIONIA:

DIOCLETIANUS:
She is mad; remove the fool. My sister is not mad; justly did she your folly reprehend.

Her rage is even more absurd, remove her from our sight and arraign the third.

Version I owes everything to naturalism, to the concept of character based on psychological realism that is a mainstay of naturalist theatre. Version II, on the other hand, bends English syntax in extraordinary ways in order to accommodate the metre and the need for archaic devices in the language. In Version II performability is not a criterion for consideration; in Version I, performability can be reduced to the lowest common denominator, that of trying to make a thousand-year-old text seem modem and closer to the conventions of contemporary stagecraft. I would want to argue that in both cases ideological concerns have dominated the translation process.

Recently, theatre studies has seen the emergence of a new field of study, one of such importance that it has grown with enormous rapidity and which is loosely termed theatre anthropology. ISTA, the International Association of Theatre Anthropology, is essentially a phenomenon of the $1980 \mathrm{~s}$, and has grown as rapidly as work in theatre semiotics has declined during the same period. One explanation for this phenomenon may lie in the fact that theatre anthropology does not prioritize the written text, nor does it stress the importance of psychological realism and the naturalist theatre. Instead, starting with the premise that all forms of theatre vary according to cultural conventions, it has sought to investigate the elements that constitute performance in different cultures. A central notion is that performance results from shifts of balance and body movement which eventually become codified. Some theatres have or have had a written text convention, but this feature is then considered as one element among many and not, as is the opinion of so many contemporary theatre scholars and so many theatre

8. Version I by Sister Mary Marguerite Butler, Hrostvitha: The Theatricality of Her Plays (New York, Philosophical Library, 1960). Version II by Katharina Wilson, The Dramas of Hrotsvit of Gandersheim (Saskatoon, Peregrina Publishing Co., 1985). 
translators, the central or fundamental element. Once this view of theatre is taken into account, then the written text ceases to appear as the quintessential yet incomplete component of theatre, and may be perceived rather as an entity in its own right that has a particular function at a given point in the development of culturally individualistic theatres.

Susan Melrose, theatre analyst and translator, has recently argued very persuasively that gestus is culture bound and cannot be perceived as a universal. Working with a multicultural group in workshop conditions, she discovered that the gestic response to written texts depends entirely on the cultural formation of the individual performer, affected by a variety of factors, including theatre convention, narrative convention, gender, age, behavioural patterns etc. In consequence, she argues for an ethnographic approach to theatre, and attacks what she sees as the tyranny of theories of the written text in the following terms:

Within this frame of speculation I might want to see it as the thrall of the literary economy over that of dramatic writing-as-scripting, of the retention of that writing within literary syllabuses within the academy, which determines the recourse to the criteria of 'fidelity' and 'equivalence' of (literary) effect in theorizing decision-making and in evaluating 'the success' or 'failure' of rewritings for the dramatic stage.?

She then goes on to attack what she calls "the neo-Platonic cringe" of certain theatre practitioners who yearn after a "'oneness' and its hypothesized access into 'truth' and 'sincerity' or 'deep meaning' or "inscribed subtext'." The importance of her argument is that she effectively demolishes the assumption that has prevailed for at least the last hundred years, that the playtext contains a series of signs which may transcend cultural boundaries. In short, performability is seen as nothing more than a liberal humanist illusion.

Theatre texts cannot be considered as identical to texts written to be read because the process of writing involves a consi-

9. Susan Melrose, "Im-Possible Enactments: From One Body to Another," paper presented at the conference Beyond Translation: Culture, History, Philosophy (University of Warwick, July 1988). 
deration of the performance dimension, but neither can an abstract notion of performance be put before textual considerations. If we are ever to advance work in theatre translation beyond case studies, then this duality will have to be taken into account. Moreover, whilst the principal problems facing a director and performers involves the transposing of the verbal into the physical, the principal problems facing the translator involve close engagement with the text on page and the need to find solutions for a series of problems that are primarily linguistic ones - differences in register involving age, gender, social position, etc., deictic units, consistency in monologues and many more. I would argue that these considerations should take precedence over an abstract, highly individualistic notion of performability, and that the satisfactory solution of such textual difficulties will result in the creation of a target language text that can then be submitted to the pre-performance readings of those who will undertake a performance. This change of emphasis may also assist to explain another unexplored and complex problem of translated theatre texts, which is their very limited life span. Whilst the source text may continue to be played unchanged for considerable time, and a prose text may continue to be read for considerable time also, the average life span of a translated theatre text is 25 years at the most. This raises all kinds of fascinating questions, and deserves more profound consideration.

My own work in this field has followed a tortuous path in the past twenty years. The work began with a belief in the commonality of the physical dimension of theatre texts, but now I have been compelled to recognize that this is physically encoded differently, is read differently and is reproduced differently across cultural boundaries. I have come to reject the notion of the encoded gestural subtext, perceiving it as a concept that belongs to a particular moment in time in western theatre history and which cannot be applied universally. What I would like to see developing in the future in this field are two main branches of investigation a historiography of theatre translation on the one hand, that would bring our knowledge into line with work already undertaken and underway in the field of prose narrative and poetry, and further investigation into the linguistic structuring of extant theatre texts, free from the shackles of the post-naturalist concept of the allpowerful, pre-performance written text that we call a play.

Note: A version of this paper was presented at the Neo-Formalist Circle Conference, Univ. of Nottingham, March 30th-April 1st 1989. 